\title{
Megarthrus of Korea, with description of a new species (Coleoptera: Staphylinidae: Proteininae)
}

\author{
Giulio Cuccodoro, Myoung Hee Kim, Kee-Jeong Ahn
}

\begin{abstract}
A taxonomic study of Megarthrus Curtis in Korea is presented. The genus is represented in Korea by 10 species including M. coreanus Kim and Cuccodoro sp. nov. Megarthrus corticalis Sharp, M. fennicus Lahtinen, M. incubifer Cuccodoro, M. japonicus Sharp, M. montanus Sawada, M. sawadai Cuccodoro, and M. zerchei Cuccodoro and Löbl are reported from Korea for the first time. A diagnosis of the genus and a key to the Korean species are provided. The new species is diagnosed, described, and illustrated and the other species are diagnosed and illustrated. Species distributions are presented, and the effect of these Korean findings on the level of endemism of the Megarthrus fauna of Japan and Far East Russia is discussed.
\end{abstract}

\begin{abstract}
Résumé-Nous présentons une étude taxonomique des Megarthrus Curtis de Corée. Le genre est représenté en Corée par 10 espèces, dont M. coreanus Kim et Cuccodoro sp. nov. Nous signalons pour la première fois en Corée la présence de $M$. corticalis Sharp, M. fennicus Lahtinen, M. incubifer Cuccodoro, M. japonicus Sharp, M. montanus Sawada, M. sawadai Cuccodoro et $M$. zerchei Cuccodoro et Löbl. Nous présentons une diagnose du genre et une clé de détermination des espèces coréennes. Nous donnons la diagnose, la description et des illustrations de la nouvelle espèce, ainsi que des diagnoses et des illustrations des autres espèces. Nous présentons les répartitions des espèces et discutons des effets de ces découvertes coréennes sur le niveau d'endémisme de la faune des Megarthrus du Japon et de la Russie d'Extrême Orient.
\end{abstract}

[Traduit par la Rédaction]

\section{Introduction}

Members of Megarthrus Curtis (Coleoptera: Staphylinidae: Proteininae) are saprophagous and (or) microphagous rove beetles with body lengths ranging from 0.8 to $2.3 \mathrm{~mm}$ (from middle of anterior pronotal margin to apex of elytral suture). They favour cool and temperate climates and are usually found in forest leaf litter, dung, carrion, and fungi. Of particular note is their ability to build up water droplets on their dorsum when filter feeding on microorganisms in decaying organic matter (Cuccodoro 1995). Within the Proteininae, they are characterized primarily by the basally narrowed eleventh antennomere (Cuccodoro 1998). Most species also have a medially grooved, laterally expanded pronotum with basally notched irregular lateral margins. Males often show striking sexual dimorphism, usually involving features on the legs but occasionally also on the head, elytra, metaventrite, or abdomen.

Since the genus was erected by Curtis (1829), nearly 140 species of Megarthrus have been described worldwide, although none have been reported for Madagascar, southern South America, Australia, or New Zealand. In the East Palaearctic region, 7 Megarthrus species have been recorded from China, 16 species from Japan, and 9 species from Far East Russia (Cuccodoro 1996, 2003; Cuccodoro and Löbl 1997). In Korea, only 2 Megarthrus species have been reported previously: $M$. hemipterus (Illiger) (as "M. heterops Sawada" in Kim et al. 1994) and M. aino Cuccodoro (Cho and Kim 2003).

Here, we describe Megarthrus coreanus Kim and Cuccodoro sp. nov. and report seven additional species collected for the first time in

Received 6 October 2010. Accepted 23 November 2010.

G. Cuccodoro, Entomology Department, Muséum d'histoire naturelle, 1211 Genève 6, Switzerland M.H. Kim, Chungnam Science High School, Gongju 314-920, Republic of Korea.

K.-J. Ahn, ${ }^{1}$ Department of Biology, Chungnam National University, Daejeon 305-764, Republic of Korea.

${ }^{1}$ Corresponding author (e-mail: kjahn@cnu.ac.kr).

doi: $10.4039 / \mathrm{n} 11-004$ 
Korea (M. corticalis Sharp, M. fennicus Lahtinen, $M$. incubifer Cuccodoro, $M$. japonicus Sharp, M. montanus Sawada, M. sawadai Cuccodoro, and $M$. zerchei Cuccodoro and Löbl). We present habitus illustrations, diagnoses, and a key to all of the Megarthrus species of Korea.

\section{Materials and methods}

Specimens used in this study have been deposited in the Chungnam National University Insect Collection, Daejeon (CNUIC), the Hannam University Natural History Museum, Daejeon (HUNHM), the Hungarian Natural History Museum, Budapest (HNHM), and the Museum of Natural History, Geneva (MHNG). Unless otherwise specified, specimens mentioned in the text are deposited in CNUIC. The terminology of taxonomic characters and measurements of specimens mainly follow Cuccodoro and Löbl (1997).

\section{Taxonomy}

\author{
Megarthrus Curtis \\ Megarthrus Curtis 1829: 28.
}

Type species: Staphylinus depressus Paykull, by subsequent designation (Westwood 1838).

Phloeobium Dejean 1833: 69.

Psyllius Gistel 1834: 9.

\section{Diagnosis}

Body length ranging from 0.8 to $2.3 \mathrm{~mm}$ (from middle of anterior pronotal margin to apex of elytral suture), fairly oval and moderately convex. Head without ocelli. Eyes 0.25 to 0.50 times as long as head, moderately convex to hemispherical, each separated from antennal insertions by broad genal gutter. Antennal scape and pedicel thick; antennomere 3 much narrower than pedicel; following antennomeres gradually broadening, not forming a distinct club; antennomere 11 narrowed at the base, ovoid or piriform. Pronotum with disc uneven, dull, variously sculptured, usually grooved medially; lateral edges not carinate and generally irregular in outline. Aedeagus with parameres obsolete and affixed to median lobe. Female ovipositor with gonocoxites fused into complex plate with large emarginations for styli.

\section{Key to Korean species of Megarthrus}

1 Frons evenly deflexed toward clypeus; maxillary palpi with third palpomere swollen, slightly longer

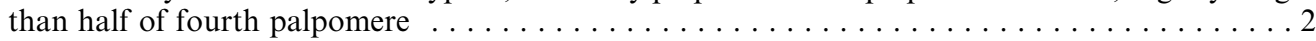
Frons forming ridge above clypeus; maxillary palpi with third palpomere fairly cylindrical, not

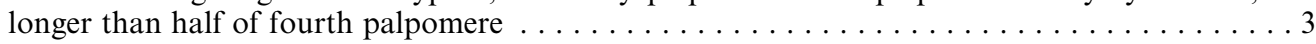

2 Pronotum markedly wider than the basal width of the elytra combined; male mesotibia deeply notched subapically (Fig. 1) . . . . . . . . . . . . . . . . . . Montanus Sawada Pronotum about as wide as the basal width of the elytra combined; male mesotibia entire

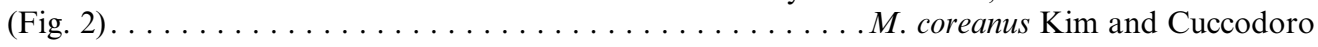

3 Anterior portion of pronotal hypomeron without oblique ridge; male with first protarsomere bear-

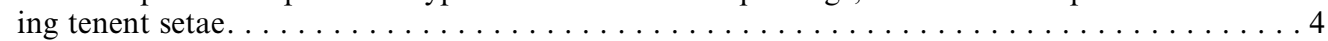
Anterior portion of pronotal hypomeron with marked oblique ridge; male with first protarsomere

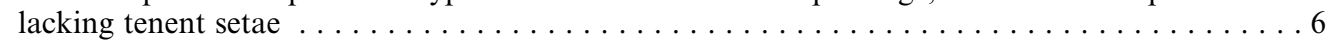

4 Pronotum blackish, about as wide as basal width of elytra combined (Fig. 3)

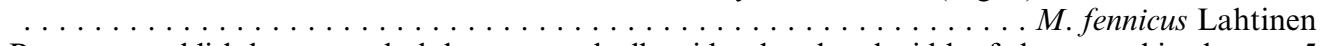
Pronotum reddish brown to dark brown, markedly wider than basal width of elytra combined . . ..5

5 Head markedly darker than pronotum; lateral outline of elytra subangulate; anteriolateral angles of pronotum projecting anteriorly; male metatibia with conspicuous adventral process (Fig. 4) . . . . . . . . . . . . . . . . . . . . . . . . hemipterus (Illiger) Head concolored with pronotum; lateral outline of elytra straight; anteriolateral angles of pronotum not projecting anteriorly; male metatibia without adventral process (Fig. 5) . . . . . . . . . . . 


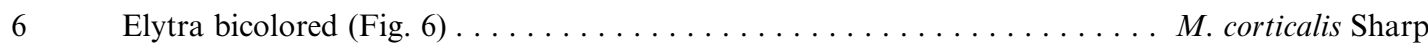

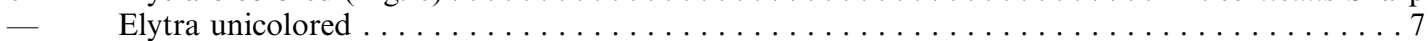

7 Body yellowish; lateral margins of pronotum arcuate (Fig. 7) . . . . . . M. aino Cuccodoro

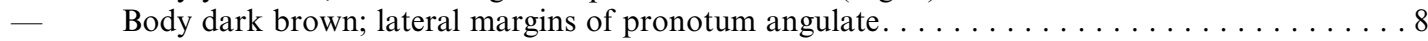

8 Scutellum rounded posteriorly; male mesotibia straight (Fig. 8) . . . . . . M. incubifer Cuccodoro

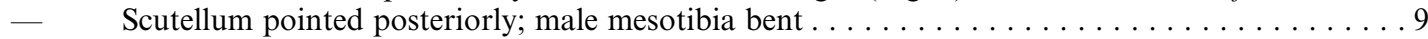

9 Lateral outline of pronotum forming three marked angles; male metatibia straight (Fig. 9) . . . .

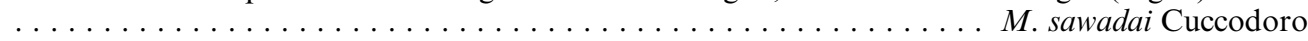
Lateral outline of pronotum forming four marked angles; male metatibia with conspicuous adven-

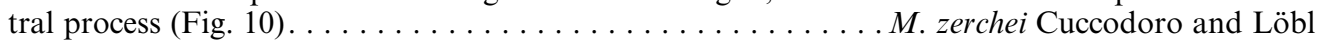

\section{Megarthrus aino Cuccodoro}

\author{
Megarthrus aino Cuccodoro 1996: 478.
}

\section{Diagnosis}

Habitus as in Figure 7. Body uniformly yellowish, about $1.1 \mathrm{~mm}$ long (from middle of anterior pronotal margin to apex of elytral suture). Frons ridged above clypeus, with medial pubescence oriented backward. Antennae bearing short and dense pubescence on articles 8 to 11 . Pronotum with lateral outline fairly arcuate, without marked angles; anterior portion of hypomeron with marked oblique ridge. Male with aedeagus symmetrical; lacking secondary sexually dimorphic features.

\section{Material examined}

KOREA: Chungnam Prov., Buyo-gun, Mt. Mansusan, 20.vii.1999, H.-J. Kim, ex sifting (1 male and 1 female); Daejeon city, Yuseong-gu, Chungnam-Univ., 16-28.vii.2003, J.-H. Choi, D.-H. Lee, S.-M. Choi, ex FIT (1 female); Mt. Gyejoksan, 14.ix.1985, Y.-B. Cho (HUNHM, 1 male); Gangwon Prov., Gosungun, Jinburyeng, 13.ix.1998, K.-J. Ahn, K.-L. You, H.-J. Lim, ex leaf litter (1 female); Chungil-myeon, Mt. Balgyosan, 4-5.vii.1998, K.-L. You, H.-J. Lim, ex FIT (2 males and 1 female); same data, but 9-10.ix.1998, K.-J. Ahn, K.-L. You, H.-J. Lim, ex sifting (1 male); Jinbu-myeon, Mt. Odaesan, 16.viii-15.ix.2001, S.-J. Park, C.-W. Shin, ex FIT (1 female); Pyongchang-gun, Pyeongchang-eup, Mt. Sambangsan, 13-15. vii.2001, K.-J. Ahn, S.-J. Park, C.-W. Shin, ex FIT in Pinus forest (1 female); Youngwol-gun, Suju-myeon, Mt. Baekdeoksan, Gwaneumsa, 13.vii-15.viii.2001, K.-J. Ahn, S.-J. Park, C.W. Shin, ex FIT (1 female); Gyengbuk Prov., Bonghwa-gun, Mt. Sundalsan, 23-25.vi.1998, K.-L. You, H.-J. Lim, ex FIT (2 males and 1 female); Gyeonggi Prov., Gapyeong-gun, Bukmyeon, Mt. Myeongjisan, 25-30.vii.2001, K.-J. Ahn, S.-J. Park, C.-W. Shin, ex FIT (2 males and 8 females in CUNIC and MHNG).

\section{Distribution and natural history}

Megarthrus aino occurs in Japan (Honshu) and South Korea. This species seems to favour elevations below $1000 \mathrm{~m}$, where it was found in forests (Pinus L. (Pinaceae)) and plantations (Cryptomeria japonica (L. f.) D. Don (Cupressaceae)) by sifting litter or using flight interception traps.

\section{Comments}

Megarthrus aino is the only member of the genus without male secondary sexually dimorphic features on the legs. It strongly resembles the Nepalese species $M$. minor Coiffait, which has a distinct aedeagus and the apical half of the metatibiae shallowly depressed in the male (Cuccodoro 2003).

\section{Megarthrus coreanus Kim and Cuccodoro, sp. nov.}

(Figs. 2, 11-22)

\section{Diagnosis}

Habitus as in Figure 2. Body reddish brown with darkened head, about $1.7 \mathrm{~mm}$ long (from middle of anterior pronotal margin to apex of elytral suture). Frons evenly deflected toward 
Figs. 1-5. Megarthrus, habitus, male: 1, M. montanus Sawada; 2, M. coreanus Kim and Cuccodoro, holotype; 3, M. fennicus Lahtinen; 4, M. hemipterus (Illiger); 5, M. japonicus Sharp. Scale bars $=1.0 \mathrm{~mm}$.
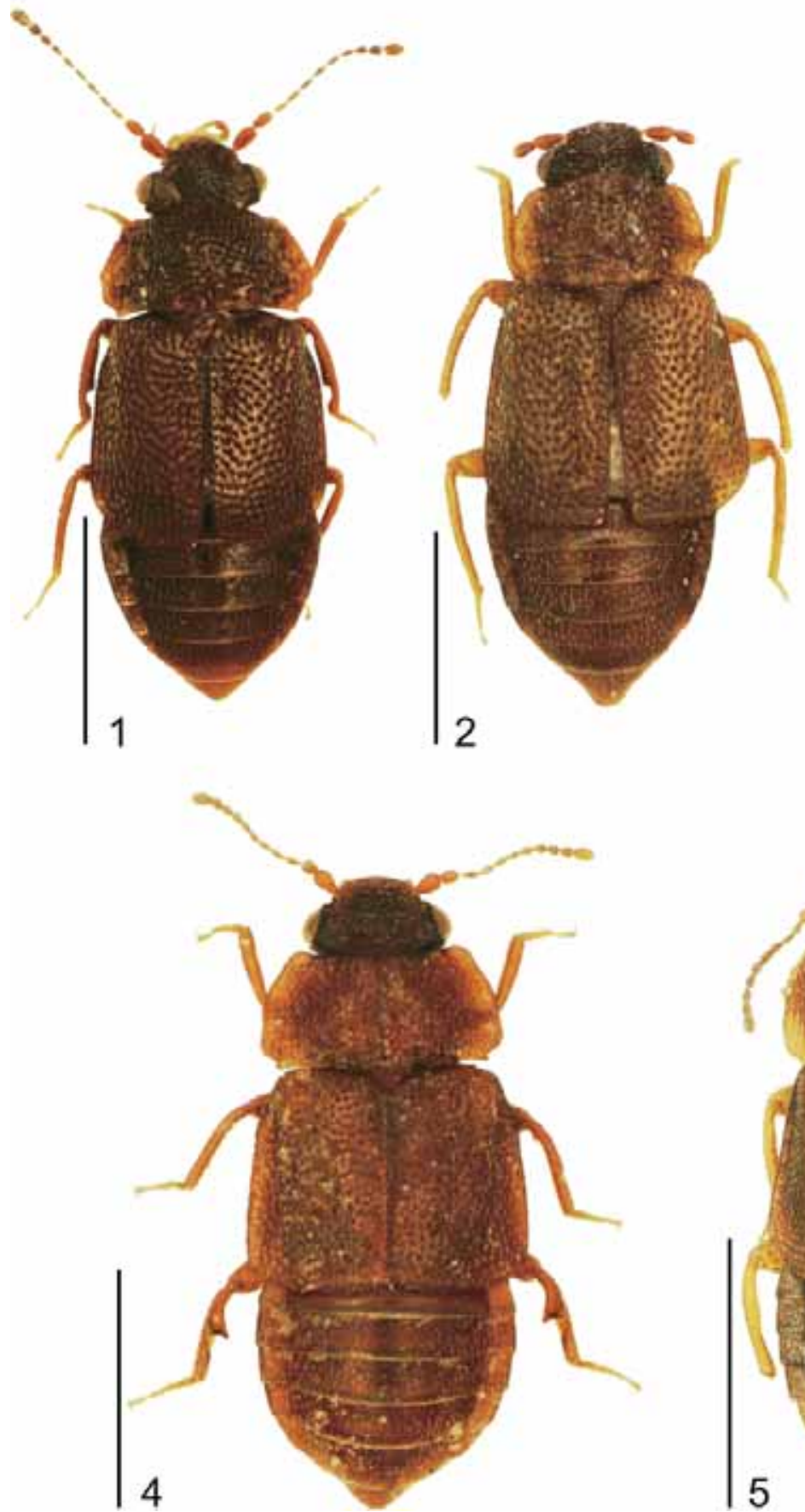
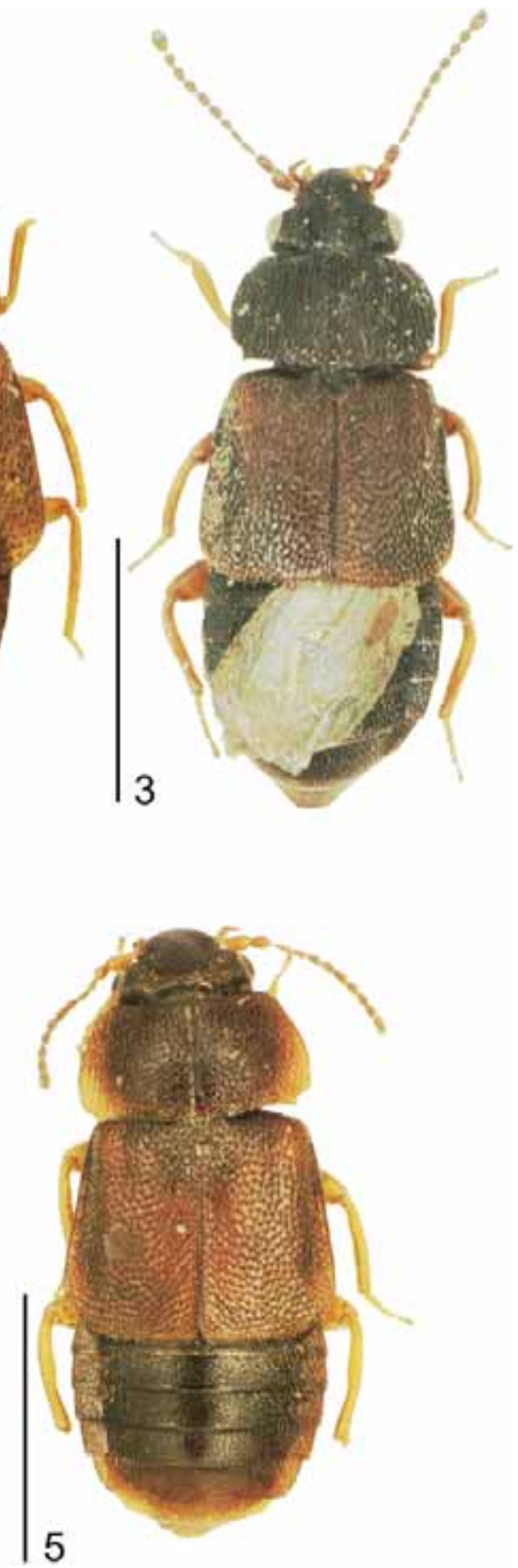
Figs. 6-10. Megarthrus, habitus, male: 6, M. corticalis Sharp; 7, M. aino Cuccodoro; 8, M. incubifer Cuccodoro; 9, M. sawadai Cuccodoro; 10, M. zerchei Cuccodoro and Löbl. Scale bars $=0.1 \mathrm{~mm}$.
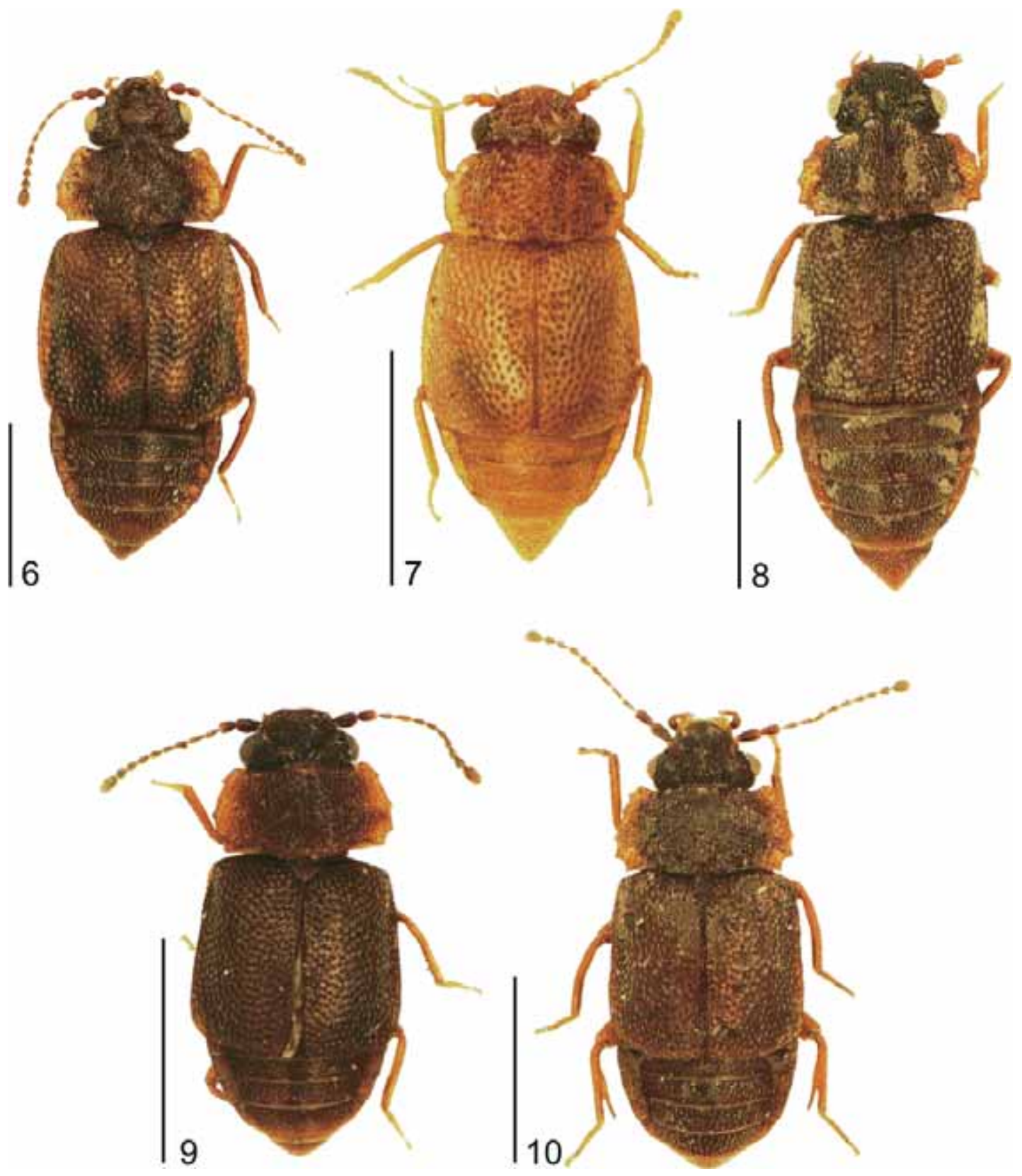

clypeus, with medial pubescence directed backward. Antennae bearing short and dense pubescence on articles 5 to 11 . Pronotum with lateral outline fairly arcuate, without marked angles; anterior portion of hypomeron with marked oblique ridge. Male with aedeagus strongly asymmetrical; peg-like setae present on protibia, mesotrochanter, mesotibia, metatrochanter, and metafemur; mesotibia entire; protarsomere 1 lacking tenent setae.

\section{Description}

Habitus as in Figure 2. Length 1.6-1.7 mm (from middle of anterior pronotal margin to 
Figs. 11-17. Megarthrus coreanus Kim and Cuccodoro, male (drawn from paratype on slide): 11, aedeagus in ventral; 12, dorsal; 13, right lateral; 14, left lateral views, parameres omitted; 15, abdominal tergite VIII in dorsal view; 16, abdominal sternite VIII in ventral view; 17, pronotum. Scale bars $=0.1 \mathrm{~mm}$.
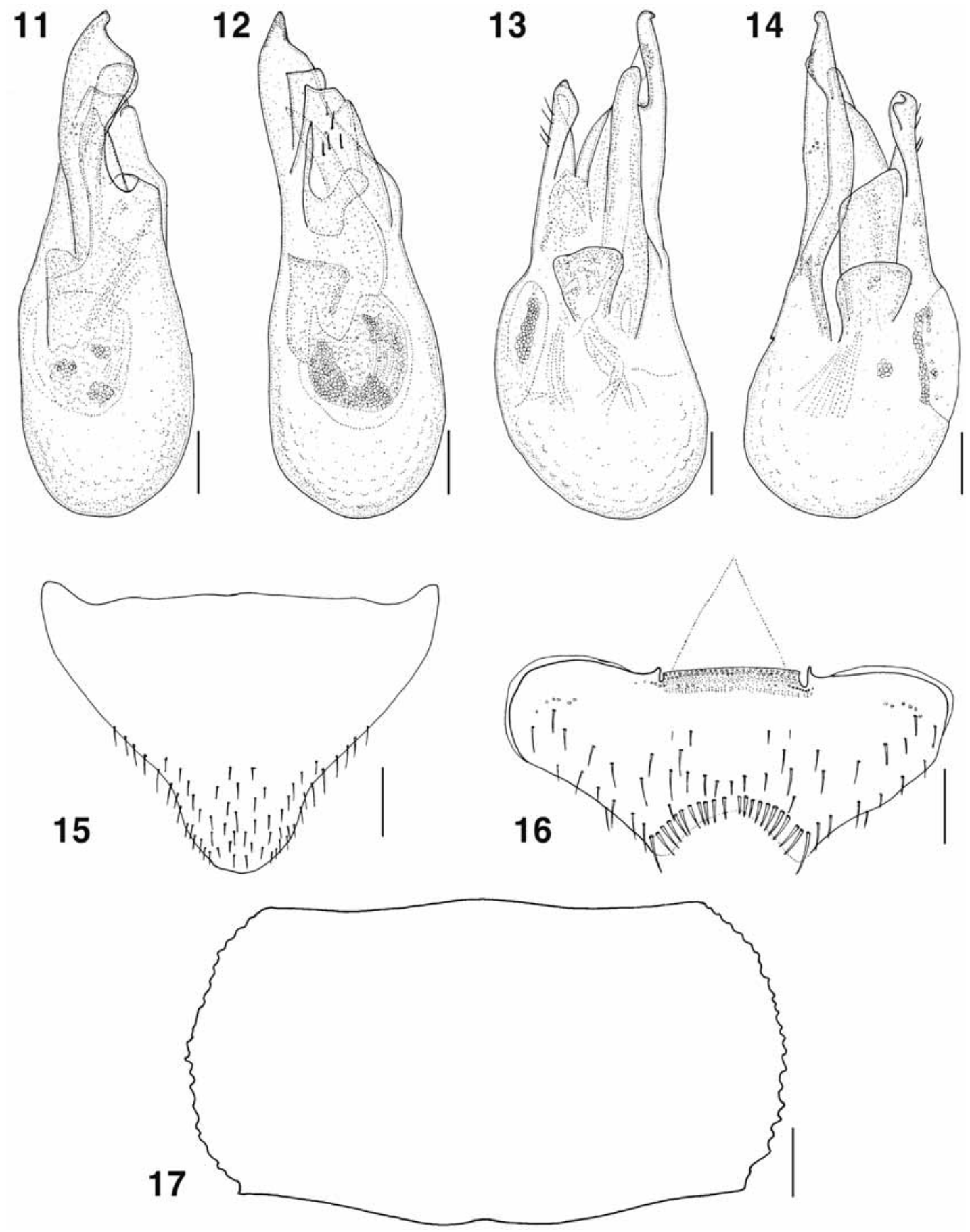
Figs. 18-22. Megarthrus coreanus Kim and Cuccodoro, male (drawn from paratype on slide): 18, mesotrochanter and mesofemur; 19, metatrochanter and metafemur; 20, protibia; 21, mesotibia; 22, metatibia. Scale bar $=0.1 \mathrm{~mm}$.
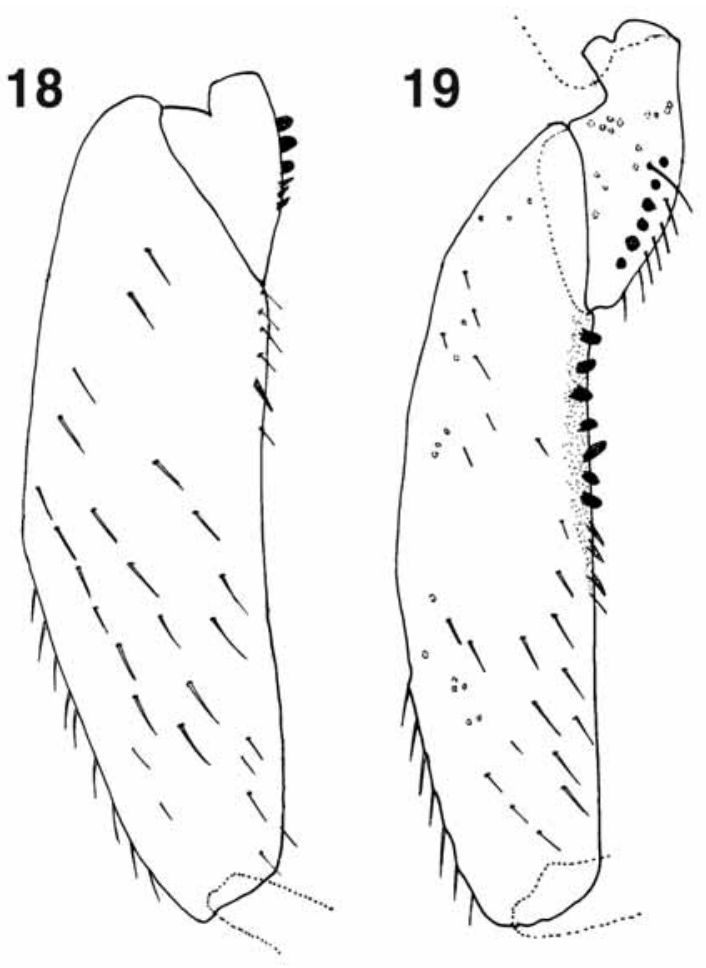

apex of elytral suture); width $0.9 \mathrm{~mm}$. Body reddish brown, with darkened head and paler appendages; antennomeres 1-7 paler than antennomeres 8-11. Dorsal pubescence fairly uniform, sparser on elytral disc; setae on medial area of frons directed backward; elytral and pronotal pubescence slightly arcuate, recumbent; metaventral pubescence becoming denser posteromedially, as long as prosternal; pubescence on abdominal tergites uniform, converging on tergites IV-VI; that on sternites parallel, uniform, except for a pair of macrosetae on each sternite. Frons and abdominal tergites very finely and sparsely granulate, with granulations not higher than half of their diameter and separated by twice their diameter or more; vertex coarsely granulofossulate; pronotum moderately granulofossulate; elytra and metaventrite coarsely punctate, relief on metaventrite becoming denser and finer posteromedially. Frons raised above level of vertex, evenly deflected toward clypeus; anterior
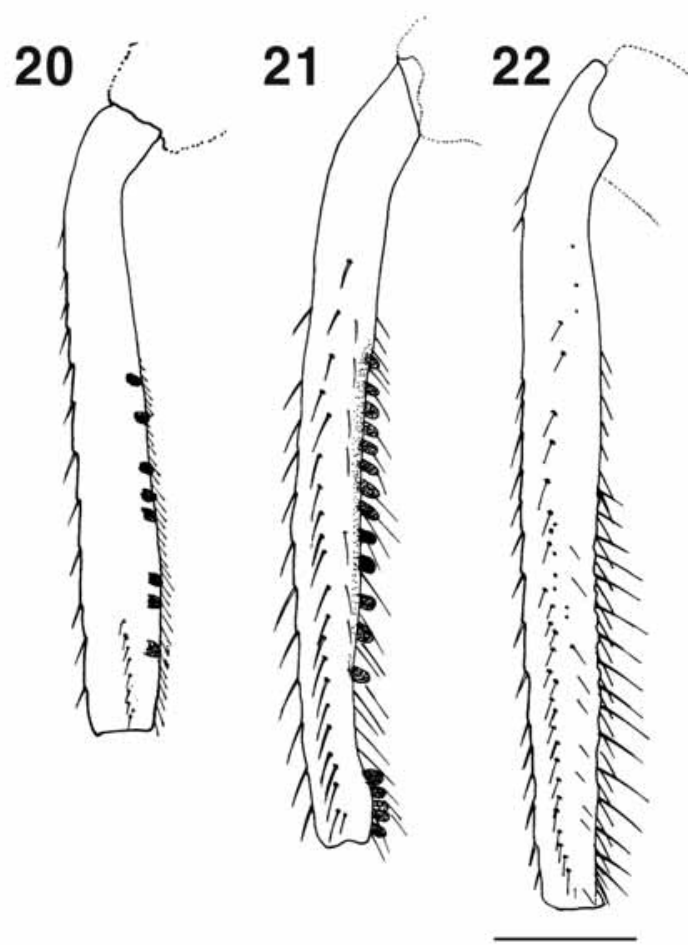

frontal margin in dorsal view weakly arcuate in middle, and laterally oblique or sinuate; mesal portion of disc strongly vaulted in lateral view; frontal impression with middle portion shallow and lateral portions deep. Eye almost hemispherical, with highest point slightly below or reaching level of vertex; supraocular margin sinuate in dorsal view. Temple and occipital ridge similar to that in Cuccodoro (1996: Fig. 1n); occipital ridge straight in middle, sinuate laterally. Antenna similar to that in Cuccodoro (1996: Fig. 20c), without patches of sensilla; scape not compressed; antennomere 3 slightly asymmetrical, 4 symmetrical; short and dense pubescence present on 5-11. Maxillary palpus with palpomere 4 about 1.6-1.8 times as long as palpomere 3. Pronotum (Fig. 17) moderately convex in frontal view; mesal portion fairly straight in lateral view; disc slightly depressed along basal portion of medial groove and moderately depressed near middle portion of lateral edge, 
latter slightly raised; medial groove shallow, parallel-sided; anterior portion of hypomeron bearing marked, oblique ridge, central area without pit. Scutellum with anterior margin angulate in middle and posterior margin slightly subangulate to sharp-angled apex. Elytron fairly rectangular; base gradually inclined, overhanging; humeral callus obsolete; elytral disc with low swellings; lateral edge finely carinate, denticulate, weakly arcuate in dorsal view; sutural margin in lateral view with anterior portion straight and posterior portion slightly arcuate; apical margin straight near suture; inner apical angle obtuse. Prosternal medial ridge present anteriorly, fine; anterior prosternal margin not bordered by longitudinal ridges. Protrochanter without transverse ridge. Metaventrite with postmesocoxal ridge arcuate in the middle; anteromedial and posteromedial ridges absent. Abdominal tergites IV-VI with basal portion flat, then slightly vaulted transversally; sternites II and III with medial processes similar to those in Cuccodoro (1996, Fig. 20h), posterior portion of process of sternite III straight.

\begin{abstract}
Male
Frontoclypeal area, metaventrite, protarsomere 5, and abdominal sternites IV-VI unmodified. Protarsomere 1 lacking tenent setae. Mesofemur (Fig. 18) slightly longer than metafemur (Fig. 19). Mesotibia (Fig. 21) slightly shorter than metatibia (Fig. 22). Metatarsomere 1 about as long as combined length of metatarsomeres $2-4$. Peg-like setae absent from protrochanter, mesofemur, and metatibia; arranged in a single row on protibia (Fig. 20), mesotrochanter (Fig. 18), mesotibia, metatrochanter (Fig. 19), and metafemur. Abdominal tergite VIII as in Figure 15. Sternite VIII as in Figure 16. Sternite IX similar to Figure 19g in Cuccodoro (1996), with marked sub-basal annular process. Aedeagus (Figs. 11-14) $0.83 \mathrm{~mm}$ long, strongly asymmetrical, with parameres hyaline and obsolete attached to median lobe.
\end{abstract}

\section{Female}

Unknown.

\section{Type material}

Holotype (male, in CNUIC): "KOREA: Gangwon Prov., Wonju-city, Chiaksan, Guryong Area, 9.vii.1999, H.-J. Kim, ex near stream". Paratypes (2): KOREA: Gangwon Prov., Wonjucity, Chiaksan, Guryong Area, 9.vii.1999, U.-S. Hwang, H.-J. Kim, ex FIT, 1 male (on slide) in MHNG; Gyeongbuk Prov., Chungsong-gun, Mt. Juwhangsan, 28-29.vi. 1987, Y.B. Cho, 1 male in HUNHM.

\section{Distribution and natural history}

This new taxon is the only Megarthrus species apparently endemic to Korea. It has been collected in the South Korean provinces of Gangwon and Gyeongbuk.

\section{Comments}

Other than M. coreanus, the only Megarthrus species to have the frons evenly deflexed toward the clypeus are the East Palaearctic species $M$. montanus and the two Nearctic species $M$. arcuatus Hatch and $M$. smetanai Cuccodoro and Löbl. This character is found elsewhere in Proteinini only in Proteinus Latreille. These Megarthrus species, which also uniquely share a rather long and unusually swollen maxillary palpomere 3 , form the M. montanus group (G. Cuccodoro, unpublished data). Among these species, $M$. coreanus is easily recognized by its pronotum, which is not markedly wider than the basal width of the elytra combined. The asymmetrical aedeagus is also a diagnostic character for this species.

Although species of the $M$. montanus group (except $M$. coreanus) are rather widely distributed, they remain quite poorly represented in collections. The limited available natural history information indicates that they inhabit rather low elevations, with no collection recorded above $1000 \mathrm{~m}$. Several singleton specimens of $M$. montanus came from sifted samples of leaf litter. Several specimens of $M$. arcuatus and $M$. smetanai were obtained from sifted samples of river flood debris (Cuccodoro and Löbl 1996). No other habitat information is available.

\section{Megarthrus corticalis Sharp}

Megarthrus corticalis Sharp 1889: 468; Sawada 1962: 10; Nakane 1963: 82; Cuccodoro 1996: 483. 


\section{Diagnosis}

Habitus as in Figure 6. Body predominantly dark brown with bicolored elytra, about $1.5 \mathrm{~mm}$ long (from middle of anterior pronotal margin to apex of elytral suture). Frons ridged above clypeus, with medial pubescence directed backward. Antennae bearing short and dense pubescence on articles 6 to 11. Pronotum with lateral outline subangulate, occasionally with up to three blunt angles; anterior portion of hypomeron with marked oblique ridge. Male with aedeagus symmetrical; peg-like setae present on mesotrochanter, mesotibia, metatrochanter, and metatibia; metatibia bearing small adventral spur on proximal third; protarsomere 1 lacking tenent setae.

\section{Material examined}

KOREA: Gangwon Prov., Jinbu-myeon, Mt. Odaesan, Sangwonsa, 4.vi-22.vi.2001, K.-J. Ahn, S.-J. Park, M.-S. Kim, M.-J. Jeon, ex FIT ( 7 males and 6 females, in CNUIC and MHNG); same data, but 30.iv-4.vi.2001 (2 males and 3 females, in CNUIC and MHNG); Ryanggang Prov., Chong-bong, $900 \mathrm{~m}, \mathrm{n}^{\circ}$ 1366, 30.vi.1988, O. Merkl and Gy. Szél (1 male in HNHM).

\section{Distribution and natural history}

Previously known only from Japan (Honshu and Shikoku), this species is recorded here for the first time from Korea. Unfortunately, no precise data are available on habitat preferences of this poorly collected species.

\section{Comments}

Megarthrus corticalis is the only Korean member of the genus with bicolored elytra. It resembles $M$. pictus Motschulsky (the only bicolored Nearctic Megarthrus species) in various aspects, although they have very different sexual characters (Cuccodoro and Löbl 1996).

\section{Megarthrus fennicus Lahtinen}

Megarthrus fennicus Lahtinen 1938: 254; Cuccodoro and Löbl 1997: 1369.

\section{Diagnosis}

Habitus as in Figure 3. Body predominantly blackish with brown elytra, about $1.1 \mathrm{~mm}$ long (from middle of anterior pronotal margin to apex of elytral suture). Frons ridged above clypeus, with medial pubescence directed backward. Antennae bearing short and dense pubescence on articles 5 to 11 . Pronotum with lateral outline arcuate anteriorly and sinuate posteriorly; anterior portion of hypomeron without marked ridge. Male with aedeagus symmetrical; peg-like setae present on protrochanter (usually 1), mesotrochanter, mesotibia, metatibia, and occasionally also on metatrochanter (at most 1); protarsomere 1 bearing tenent setae.

\section{Material examined}

KOREA: Ryanggang Prov., $31 \mathrm{~km}$ on Paekdu-san road, NW of Samjiyon, $2000 \mathrm{~m}$, $\mathrm{n}^{\circ}$ 1356, 28.vi.1988, O. Merkl and Gy. Szél (1 male in HNHM).

\section{Distribution and natural history}

Megarthrus fennicus is a rather poorly collected species occurring over an apparently disjunct range in northern Europe and Transbaikalian Siberia (Cuccodoro and Löbl 1997). Its identification in North Korea (new to Korea), where it seems confined to quite high elevations $(2000 \mathrm{~m})$, represents the southernmost record of the species. In Finland, it was collected from dead fish and human excrement (Lahtinen 1938).

\section{Comments}

In Korea, M. fennicus is the only known member of the genus with blackish head, pronotum, and abdomen. It is distinguished from the other northern European species M. strandi Scheerpeltz by sexual characters (Cuccodoro and Löbl 1997).

\section{Megarthrus hemipterus (Illiger)}

Silpha hemiptera Illiger 1794: 597.

Staphylinus melanocephalus Olivier 1795: 38. Phloebium nitiduloides Lacordaire 1835: 493.

Megarthrus hemipterus: Erichson 1839: 645; Sharp 1889: 468; Sawada 1962: 14; Cuccodoro 1996: 485; Cuccodoro and Löbl 1997: 1372.

Megarthrus heteropus Sawada 1962: 14 [misspelled as $M$. heterops in Watanabe 1994: 264; Kim et al. 1994: 139; Cho and Ahn 2001: 51]. 


\section{Diagnosis}

Habitus as in Figure 4. Body predominantly reddish brown with markedly darker head, about 1.3-1.6 mm long (from middle of anterior pronotal margin to apex of elytral suture). Frons ridged above clypeus, with medial pubescence directed backward. Antennae bearing short and dense pubescence on articles 5 to 11 . Pronotum with lateral outline subangulate usually with three blunt angles; anterior portion of hypomeron without marked ridge. Male with aedeagus symmetrical; peg-like setae present on mesotrochanter, mesotibia, metatrochanter, and metatibia; metatibia with conspicuous tooth-like adventral process; protarsomere 1 lacking tenent setae.

\section{Material examined}

KOREA: Chungbuk Prov., Boeun-gun, Songnisan, 12.ix.1999, M.-H. Kim, ex mushroom (Russula sp.) (1 female); Jecheon City, Mt. Waraksan, Songwon valley, 4.viii.2000, U.-S. Hwang, ex mushroom (2 males and 4 females); Danyang-gun, Yeongchun-myeon, Mt. Taewhasan, 14.vii-14.viii.2001, K.-J. Ahn, S.-J. Park, C.-W. Shin, ex FIT (38 males and 45 females); Chungnam Prov., Daejeon City, Mt. Sikjangsan, 5.viii.2000, M.-H. Kim, ex a little rotten mushroom (10 males and 13 females); ex entirely rotten mushroom (4 males); Mt. Gyeryongsan, Geumsubong, 18.vii.2001, S.-J. Park, ex mushroom (1 female); Gangwon Prov., Hoengseong-gun, Gangrim-myeon, Mt. Chiaksan, 15.viii.2000, M.-H. Kim, ex rotten mushroom (Boletaceae) (13 males and 6 females); Nae-myeon, Mt. Kyebangsan Unduryeong, 18.viii.2000, M.-H. Kim, ex mushroom (1 male); Inje-gun, Jumbongsan, Gombaeryoung, 23-30.viii.1999, U.-S. Hwang, ex bait trap (4 males and 10 females); Sangnam-myeon, Mt. Bangtaesan, 18.viii.2000, M.-H. Kim, ex mushroom (2 males and 4 females); 29.vii.2000, U.-S. Hwang, S.-J. Park (1 female); Pyongchang-gun, Bangrim-myeon, Mt. Baeduksan, 12.vii-16.viii. 2001, K.-J. Ahn, S.-J. Park, C.-W. Shin, ex FIT (6 males and 10 females); Jinbu-myeon, Mt. Odaesan, Sangwonsa, 28-30.viii.1998, K.-L. You, K.-J. Ahn, ex mushroom (1 female); 22. viii.2000, K.-J. Ahn, J.-H. Ahn (1 male and 1 female); 22.viii.2000, M.-H. Kim, ex mushroom (10 males and 13 females); ex mushroom (1 male); 22.viii.2000, M.-H. Kim, ex mushroom (musty Boletaceae) (3 males and 2 females); ex mushroom (11 females); 22.viii-20.x.2000, K.-J. Ahn, ex FIT (4 females); mushroom (1 female); 23.viii.2000, M.-H. Kim, ex mushroom (1 male and 5 females); 16.viii.2001, M.-H. Kim, ex mushroom (Tricholomataceae) (1 male); 16.viii. 2001, M.-H. Kim, ex entirely rotten mushroom (Boletaceae) (2 males and 3 females); 23.viii. 2001, M.-J. Jeon, ex under rotten mushroom (2 male); 4-22.vi.2001, K.-J. Ahn, S.-J. Park, M.-S. Kim, M.-J. Jeon, ex FIT (5 males and 1 female); 22.vi-16.viii.2001, S.-J. Park, C.-W. Shin, ex FIT (36 males and 25 females, in CNUIC and MHNG); 16.viii-15.ix.2001, S.-J. Park, C.-W. Shin, ex FIT (5 males and 13 females, in CNUIC and MHNG); 15.ix-14.xi. 2001, K.-J. Ahn, C.-W. Shin, ex FIT (1 male and 1 female); N37.78711 E128.56319, 25.vii. 2003, D.-H. Lee, S.-M. Choi, ex sifting (1 female); Bukdaesa, 23.viii.2000, M.-J. Jeon, ex entirely rotten mushroom (Boletaceae) (1 male); ex mushroom (1 female); J.-H. Ahn, ex mushroom (3 females); Jin-gogae, 23.viii.2000, M.-H. Kim, ex mushroom (1 male and 2 females); 23.viii.2000, M.-H. Kim, ex entirely rotten mushroom (1 male); Tongpikol camp complex, 7-9.vii.1998, K.-L. You, ex FIT (1 male); Woljeongsa, 22.viii.2000, M.-J. Jeon, ex under rotten mushroom ( 2 females); ex leaf litter (1 female); 23.viii.2000, M.-J. Jeon, ex under rotten mushroom (1 female); 23.viii.2000, U.-S. Hwang, ex mushroom (1 female); Mt. Sambangsan, 13.vii-15.viii.2001, K.-J. Ahn, S.-J. Park, C.-W. Shin, ex FIT in Pinus forest (56 males and 84 females, in CNUIC and MHNG); Yangyang-gun, Mt. Seolaksan, 16.viii.2000, M.-H. Kim, ex entirely rotten mushroom (1 female); Yeongwol-gun, Yeongwol-eup, Taehwasan, 14.viii.2001, M.-H. Kim, ex mushroom (Boletaceae) (2 males and 2 females); Wonju city, Mt. Chiaksan Sangwonsa, 14.viii.2000, M.-H. Kim, ex mushroom (6 males and 9 females); Gyeongbuk Prov., Sangju City, Mt. Cheontaeksan, 6.viii.2000, M.-H. Kim, ex mushroom (7 males and 7 females); mushroom (1 male); mushroom (2 males and 1 female); mushroom (1 female); 10.ix.2000, M.-H. Kim, ex decayed mushroom (Boletaceae) (4 males and 5 females); ex decayed mushroom (Boletaceae) (1 female); 27.vii.2001, M.-H. Kim, ex 
mushroom (Boletaceae) (4 males and 2 females); decayed Boletaceae (3 females); mushroom (Amanitaceae) (1 female); mushroom (Cortinariaceae) (1 female); Yeongyang-gun, Subi-myeon, Mt. Ulyeonsan, 12-14.vii.2001, Y.-B. Cho, ex bait trap (HUNHM, 3 males); Gyeonggi Prov., Gapyeong-gun, Buk-myeon, Mt. Myeongjisan, 25-30.vii.2001. K.-J. Ahn, S.-J. Park, C.-W. Shin, ex FIT (15 males and 10 females); Yangju-gun, Jangheung-myeon, Mt. Bukhansan, 26.vii-31.viii.2001, K.-J. Ahn, S.-J. Park, C.-W. Shin, ex FIT (1 male and 1 female); Jeonbuk Prov., Wanju, Dongsang, 26.vii.1991, J.-Y. Choi (1 male).

\section{Distribution and natural history}

Distributed without major gaps from the British Isles, Fennoscandia, and Europe (except the Mediterranean area) to China, Far East Russia, and Japan (Hokkaido, Honshu, and Shikoku), M. hemipterus is the most widespread member of the genus. In Korea it is most likely close to its southeastern distributional limit. In Korea, this species has been found abundantly in fresh and rotten fungi (Amanitaceae, Boletaceae, Cortinariaceae, Russulaceae Russula sp., Tricholomataceae). Elsewhere, it has been collected in carrion, fungi, leaf litter, and various types of decaying organic matter (Cuccodoro and Löbl 1997).

\section{Comments}

Megarthrus hemipterus strongly resembles the Chinese species $M$. dentipes Bernhauer and the trans-Himalayan species $M$. flavolimbatus Cameron, which have slightly different sexual characters (Cuccodoro and Löbl 1997; Cuccodoro 2003).

\section{Megarthrus incubifer Cuccodoro}

Megarthrus incubifer Cuccodoro 1996: 486.

\section{Diagnosis}

Habitus as in Figure 8. Body dark brown, about $1.5 \mathrm{~mm}$ long (from middle of anterior pronotal margin to apex of elytral suture). Frons ridged above clypeus, with medial pubescence directed forward. Antennae bearing short and dense pubescence on articles 5 to 11. Pronotum with lateral outline markedly subangulate, forming two blunt angles; anterior portion of hypomeron with marked oblique ridge. Male with aedeagus symmetrical; peg-like setae present on mesotibia, mesotrochanter, and metatibia; protarsomere 1 lacking tenent setae.

\section{Material examined}

KOREA: Gangwon Prov., Jeongsun-gun, Gohan-eup, Mt. Hambaeksan, 13.vii.1999, U.-S. Hwang, H.-J. Kim, ex FIT (1 female); Pyongchang-gun, Jinbu-myeon, Mt. Odaesan, 4-22.vi.2001, K.-J. Ahn, S.-J. Park, M.-S. Kim, M.-J. Jeon, ex FIT (2 males and 1 female); 22.vi-16.viii.2001, S.J. Park, C.-W. Shin, ex FIT (2 males); Pyeongchang-eup, Mt. Sambangsan, 13.vii-15.viii.2001, K.-J. Ahn, S.-J. Park, C.-W. Shin, ex FIT in Pinus forest (19 males and 21 females, in CNUIC and MHNG); Wonju-city, Mt. Chiaksan, Guryong Area, 10.vii.1999, U.-S. Hwang, H.-J. Kim, Y.-J. Jeong, ex sifting (3 males and 4 females); U.-S. Hwang, H.-J. Kim, ex FIT (1 male); Gyeongbuk Prov., Ulsan city, Sangbukmyeon, Mt. Gajisan, near Baenae-gogae, 3.vii. 2001, Y.-B. Cho, ex sifting (HUNHM, 1 male and 1 female); Gyeonggi Prov., Gapyeong-gun, Buk-myeon, Mt. Myeonggisan, 25.vii-30.viii. 2001, K.-J. Ahn, S.-J. Park, C.-W. Shin, ex FIT (1 female).

\section{Distribution and natural history}

Previously known only from Japan (Hokkaido and Shikoku), M. incubifer is recorded here from South Korea (new to Korea). The largest series (40 individuals) came from a flight intercept trap left from mid-July to mid-August in a Pinus forest.

\section{Comments}

Megarthrus incubifer resembles in many aspects the Himalayan species M. elevatus Coiffait. The latter species, found predominantly in leaf litter at elevations ranging from 2000 to $3500 \mathrm{~m}$, has quite different sexual characters (Cuccodoro 2003).

\section{Megarthrus japonicus Sharp}

Megarthrus japonicus Sharp 1874: 99; Sawada 1962: 12; Nakane 1963: 82; Cuccodoro 1996: 
488; Cuccodoro and Löbl 1997: 1375; Watanabe 1998: 313.

\section{Diagnosis}

Habitus as in Figure 5. Body brown with darkened head, about $1.3 \mathrm{~mm}$ long (from middle of anterior pronotal margin to apex of elytral suture). Frons ridged above clypeus, with medial pubescence directed backward. Antennae bearing short and dense pubescence on articles 5 to 11 . Pronotum with lateral outline fairly arcuate anteriorly, and sinuate or angulate posteriorly; anterior portion of hypomeron without marked ridge. Male with aedeagus symmetrical; peg-like setae present on mesotrochanter, mesotibia, metatrochanter, and metatibia; protarsomere 1 bearing tenent setae.

\section{Material examined}

KOREA: Gangwon Prov., Chunsung-gun, Suchun-ri, 16.ix.1984, J.-I. Kim (1 male); Gyeongnam Prov., Sachun-gun, Guam-ri, 10.v.1986, K.-S. Lee (1 female); Jeju Prov., Gashiri, 2.v.1985, K.-S. Lee, 1 female; 5.v. 1985, K.-S. Lee, ex vegetable (1 female).

\section{Distribution and natural history}

Megarthrus japonicus is an East Palaearctic species known from Siberia, Far East Russia, North China, and Japan. It is recorded here for the first time from Korea. Its habitat preferences remain unclear.

\section{Comments}

Megarthrus japonicus strongly resembles the trans-Palaearctic species $M$. nitidulus Kraatz, which has different sexual characters and has been collected in a wide range of habitats (Cuccodoro and Löbl 1997).

\section{Megarthrus montanus Sawada}

Megarthrus montanus Sawada 1962: 15; Cuccodoro 1996: 489; Cuccodoro and Löbl 1997: 1381.

\section{Diagnosis}

Habitus as in Figure 1. Body dark brown, about $1.5 \mathrm{~mm}$ long (from middle of anterior pronotal margin to apex of elytral suture).
Frons evenly deflected toward clypeus, with medial pubescence directed backward. Antennae bearing short and dense pubescence on articles 5 to 11. Pronotum with lateral outline subangulate, usually forming two blunt angles; anterior portion of hypomeron with marked oblique ridge. Male with aedeagus symmetrical; peg-like setae present only on mesotibia; mesotibia subapically deeply notched; protarsomere 1 lacking tenent setae.

\section{Material examined}

KOREA: Gangwon Prov., Pyeongchanggun, Jinbu-myeon, Mt. Odaesan, Sangwonsa, 30.iv-4.vi.2001, K.-J. Ahn, S.-J. Park, M.-S. Kim, M.-J. Jeon, ex FIT (1 female); same data, but 4-22.vi.2001, K.-J. Ahn, S.-J. Park, M.-S. Kim, M.-J. Jeon, ex FIT (1 male); same data, but 22.vi-16.viii.2001, S.-J. Park, C.-W. Shin, ex FIT (1 male); same data, but $<37^{\circ} 47^{\prime} 4.7^{\prime \prime}$ $\mathrm{N} ; 128^{\circ} 34^{\prime} 18.7^{\prime \prime} \mathrm{E}>829 \mathrm{~m}, 31 . \mathrm{v} .2008$, J.G. Lee, T.K. Kim, ex sifting leaf litter (1 female in CNUIC and 1 female in MHNG); Wonjucity, Chiaksan, Guryong Area, 10.vii.1999, U.-S. Hwang, H.-J. Kim, Y.-J. Jeong, ex sifting (2 females); same data, but U.-S. Hwang, H.-J. Kim, ex FIT (1 female); Gyeonggi Prov., Namyangju City, Sudong-myeon, Chukryongsan, 13.ix.1999, U.-S. Hwang, H.-J. Kim, ex sifting (1 male).

\section{Distribution and natural history}

Megarthrus montanus is an East Palaearctic species known from Siberia, Far East Russia (Sikhote-Alin range), North China, and Japan (Honshu). It is recorded here for the first time from Korea. The few available specimens of this species are mostly singletons extracted from sifted samples of forest leaf litter. Some individuals are brachypterous (Cuccodoro 1996).

\section{Comments}

See comments under $M$. coreanus.

\section{Megarthrus sawadai Cuccodoro}

Megarthrus sawadai Cuccodoro 1996: 492.

\section{Diagnosis}

Habitus as in Figure 9. Body dark brown, about $1.2 \mathrm{~mm}$ long (from middle of anterior 
pronotal margin to apex of elytral suture). Frons ridged above clypeus, with medial pubescence directed backward. Antennae bearing short and dense pubescence on articles 5 to 11 (misquoted as 7 to 11 in Cuccodoro 1996). Pronotum with lateral outline forming three marked angles; anterior portion of hypomeron with marked oblique ridge. Male with aedeagus symmetrical; peg-like setae present on mesotrochanter, mesotibia, and metatibia; metatibia straight; protarsomere 1 lacking tenent setae.

\section{Material examined}

KOREA: Chungnam Prov., Geumsan-gun, Mt. Daedunsan, 25.v.2001, S.-J. Park, M.J. Jeon, H.-J. Yun, ex sifting (1 female); Gangwon Prov., Jinbu-myeon Dongsan-ri Odaesan Sangwonsa, 15.ix-14.xi.2001, K.-J. Ahn, C.-W. Shin, ex FIT (1 male); Wonju-city, Chiaksan, Guryong Area, 10.vii.1999, U.-S. Hwang, H.-J. Kim, Y.-J. Jeong, ex sifting (1 male); Jeonnam Prov., Gwangyang city, Daab-myeon, Eochi-ri, 25.v.2000, H.-J. Kim, M.-J. Jeon, ex sifting (2 males and 3 females, in CNUIC and MHNG); Jeju Prov., Namjeju-gun, Geopyeoi-oreum, 28. v.2003, S.-J. Park, C.-W. Shin, M.-J. Jeon, ex sifting (1 female); 5.v.1885, K.-S. Lee, ex vegetable (1 female).

\section{Distribution and natural history}

Megarthrus sawadai is new to Korea. It was known previously only from two males from Japan (Honshu), one of which was extracted from a sifted sample of forest leaf litter. The Korean specimens were collected by sifting and using flight intercept traps.

\section{Comments}

Megarthrus sawadai strongly resembles the Japanese species $M$. parallelus Sharp, which has markedly different sexual characters (Cuccodoro 1996).

\section{Megarthrus zerchei Cuccodoro and Löbl}

Megarthrus zerchei Cuccodoro and Löbl 1997: 1406.

\section{Diagnosis}

Habitus as in Figure 10. Body dark brown, about $1.2 \mathrm{~mm}$ long (from middle of anterior pronotal margin to apex of elytral suture). Frons ridged above clypeus, with medial pubescence directed backward. Antennae bearing short and dense pubescence on articles 6 to 11. Pronotum with lateral outline forming four marked angles; anterior portion of hypomeron with marked oblique ridge. Male with aedeagus symmetrical; peg-like setae present on mesotrochanter, mesotibia, and metatibia; metatibia with long adventral process projecting from middle of tibia to its apex; protarsomere 1 lacking tenent setae.

\section{Material examined}

KOREA: Ryanggang Prov., $31 \mathrm{~km}$ on Paekdu-san road, NW of Samjiyon, $2000 \mathrm{~m}$, $\mathrm{n}^{\circ}$ 1355, 28.vi.1988, O. Merkl and Gy. Szél (1 male in HNHM); Ryanggang Prov., $31 \mathrm{~km}$ on Paekdu-san-milyong, $1500 \mathrm{~m}, \mathrm{n}^{\circ}$ 1353, 27.vi. 1988, O. Merkl and Gy. Szél (1 male in MHNG and 1 female in HNHM).

\section{Distribution and natural history}

Known previously only from Far East Russia (Sikhote-Alin range), this species is reported here from North Korea for the first time. No precise habitat data are available for this species.

\section{Comments}

Megarthrus zerchei strongly resembles the Nepalese species $M$. calcaratus Coiffait, which occurs in forest leaf litter at quite high elevations (3150-3700 m) and has slightly different sexual characters (Cuccodoro 2003).

\section{Discussion}

This study increases the number of Megarthrus species known to occur in the Korean peninsula from 2 to 10. One species (M. coreanus) is apparently endemic to the area. Of the remaining species, one was previously known to be uniquely shared by Japan and Korea (M. aino), four were previously considered endemic to either Japan (M. corticalis, M. incubifer, and M. sawadai) or Far East Russia (M. zerchei), two are widespread in the East Palaearctic region (M. japonicus and M. montanus), one also occurs in Fennoscandia and in Transbaikalian Russia (M. fennicus), and the last is trans-Palaearctic (M. hemipterus). 
Although the diversity of Korean Megarthrus may appear high compared with other larger north temperate regions, such as Central and Southern Europe (seven species), Fennoscandia (eight species), and North America (12 species), it remains lower than that of nearby Japan (16 species). Although the Japanese archipelago remains an area of relatively high endemism for Megarthrus, these new Korean findings decrease the number of Megarthrus species considered endemic to the Japanese archipelago from nine $(56 \%)$ to six $(37 \%)$.

Only five specimens of Megarthrus from North Korea (Ryanggang Prov.) were available for this study. These represent three species (M. corticalis, M. fennicus, and M. zerchei), the latter two of which are unknown from South Korea. Further collecting in North Korea will likely reveal additional Megarthrus species, such as $M$. nigrinus Sahlberg (its distribution is very similar to that of M. fennicus), the East Palaearctic species $M$. conspirator Cuccodoro, and the three trans-Palaearctic species $M$. denticollis (Beck), M. depressus (Paykull), and M. nitidulus Kraatz.

\section{Acknowledgments}

We thank Y.B. Cho (HUNHM) and Otto Merkl (HNHM) for providing valuable specimens for this study. We are also grateful to T.-K. Kim (CNUIC) for formatting the manuscript, including illustrations. This research was supported by a National Institute of Biological Resources (NIBR) project on the survey and excavation of Korean indigenous species under the Ministry of Environment, Korea.

\section{References}

Cho, Y.B., and Ahn, K.-J. 2001. Economic insects of Korea 11: Coleoptera (Silphidae, Staphylinidae). Insecta Koreana, Supplement, 18: 1-167.

Cho, Y.B., and Kim, M.H. 2003. Staphylinidae (Coleoptera) fauna of Ulleung-do, Korea. Korean Journal of Environmental Biology, 21: 126131.

Cuccodoro, G. 1995. Two new species of Megarthrus (Coleoptera, Staphylinidae, Proteininae) and a note on 'water loading' behaviour. Journal of Zoology, 236: 253-264. doi:10.1111/j.14697998.1995.tb04492.x.
Cuccodoro, G. 1996. Revision of the Japanese rovebeetles of the genus Megarthrus (Coleoptera, Staphylinidae, Proteininae). Revue Suisse de Zoologie, 103: 475-524.

Cuccodoro, G. 1998. Revision and phylogeny of Megarthrus Curtis 1829 from New Guinea, New Caledonia and Fiji (Coleoptera Staphylinidae Proteininae). Tropical Zoology, 11: 103-137.

Cuccodoro, G. 2003. A revision of Megarthrus Curtis of India, Nepal and Sri Lanka (Coleoptera, Staphylinidae, Proteininae). In Systematics of Coleoptera: papers celebrating the retirement of Ivan Löbl, Memoirs on Entomology, International 17. Edited by G. Cuccodoro and R.A. Leschen. Associated Publishers, Gainesville, Florida. pp. 359-455.

Cuccodoro, G., and Löbl, I. 1996. Revision of the rove beetles of the genus Megarthrus of America north of Mexico (Coleoptera: Staphylinidae: Proteininae). Mitteilungen Münchner Entomologischen Gesellschaft, 86: 145-188.

Cuccodoro, G., and Löbl, I. 1997. Revision of the Palaearctic rove beetles of the genus Megarthrus (Coleoptera: Staphylinidae: Proteininae). Journal of Natural History, 31: 1347-1415. doi:10.1080/ 00222939700770761.

Curtis, J. 1829. A guide to an arrangement of British insects: being a catalogue of all the named species hitherto discovered in Great Britain and Ireland. J. Curtis, London, United Kingdom.

Dejean, P.F.M.A. 1833. Catalogue des Coléoptères de la collection de M. Le Comte Dejean. 2nd ed. 1 st issue. Méquignon-Marvis Père et Fils, Paris, France. pp. 1-96.

Erichson, W.F. 1839. Die Käfer der Mark Brandenburg, Erster Band. Zweite Abteilung. Morin, Berlin, Germany. pp. 385-740.

Gistel, J. 1834. Die Insecten-Doubletten aus der Sammlung des Herrn Grafen Rudolph von Jenison Walworth zu Regensburg, welche sowohl im Kauf als im Tausche abgegeben werden, No. 1, Käfer. George Jaquot, München, Germany.

Illiger, J.K.W. 1794. Beschreibung einiger neuen Käferarten aus der Sammlung des Herrn Professors Hellwig in Braunschweig, 5. In Neuestes Magazin für die Liebhaber der Entomologie. Edited by D. Schneider. Christian Lorenz Strucks, Stralsund, Germany. pp. 593-620.

Kim, J.-I., Kwon, Y.-J., Paik, J.-C., Lee, S.-M., Ahn, S.-L., Park, H.-C., and Chu, H.-Y. 1994. Order 23. Coleoptera. In Check list of insects from Korea. Edited by The Entomological Society of Korea and Korean Society of Applied Entomology. Kon-Kuk University Press, Seoul, South Korea. pp. 117-214.

Lacordaire, J.T. 1835. In Faune entomologique des environs de Paris, ou species général des insectes qui se trouvent dans un rayon de quinze à vingt lieues aux alentours de Paris. Edited by J.B.A. Boisduval and J.T. Lacordaire. Vol. 1. MéquignonMarvis, Paris, France. 
Lahtinen, E.K. 1938. Eine neue Megarthrus-Art (Col., Staphylinidae) aus Finnland. Annales Entomologici Fennici, 4: 254-256.

Nakane, T. 1963. Staphylinidae. In Iconographia insectorum Japonicorum colore naturali edita. Vol. 2 (Coleoptera). Edited by T. Nakane, K. Ohbayashi, S. Nomura, and Y. Kurosawa. Hokuryukan, Tokyo, Japan. pp. 81-100.

Olivier, A.G. 1795. Entomologie ou histoire naturelle des insectes, avec leurs caractères génériques et spécifiques, leur description, leur synonymie, et leur figure enluminée. Coléoptères, 3: 1-557.

Sawada, K. 1962. On some new species of Megarthrus Curtis from Japan (Coleoptera: Staphylinidae). Entomological Review of Japan, 15: 9-16.

Sharp, D.S. 1874. The Staphylinidae of Japan. Transactions of the Entomological Society of London, 1874: 1-103.
Sharp, D.S. 1889. The Staphylinidae of Japan. Annals and Magazine of Natural History, 6(3): 463-476.

Watanabe, Y. 1994. Staphylinidae (Proteininae). In The Coleoptera of Japan in color. Vol. II. Edited by S.-I. Uéno, Y. Kurosawa, and M. Satô, Hoikusa, Osaka, Japan. pp. 263-264.

Watanabe, Y. 1998. New records of staphylinid beetles (Coleoptera) from Shimo-koshiki-jima island of the Koshiki Islands of southwestern Kyushu, Japan. Elytra, 26: 313-314.

Westwood, J.O. 1838. Synopsis of the genera of British insects. In An introduction to the modern classification of insects; founded on the natural habits and corresponding organisation of the different families, vol. 2. Longman, Orme, Brown, Green, and Longmans, London, United Kingdom. pp. 1-48. 